\title{
Quantification and genotyping of PCV2 DNA in the tissues of PCV2-infected conventional pigs with different clinical signs
}

\author{
Hye Kwon Kim ${ }^{1, \uparrow}$, Yuzi Luo ${ }^{1, \dagger}$, Hyoung Joon Moon ${ }^{2}$, Seong Jun Park ${ }^{1}$, Se Mi Rho' ${ }^{1}$ Jae Yeon Han ${ }^{1}$, \\ Van Giap Nguyen ${ }^{1}$, Bong Kyun Park ${ }^{1, *}$ \\ ${ }^{1}$ College of Veterinary Medicine and BK21 Program for Veterinary Science, Seoul National University, \\ Seoul 151-742, Korea \\ ${ }^{2}$ Research Unit, Green Cross Veterinary Products, Yongin 449-903, Korea
}

(Accepted: December 24, 2010)

\begin{abstract}
This study was focused on the genotyping and quantification of Porcine circovirus type 2 (PCV2) in thirty PCV2-positive pigs with different clinical symptoms (PCV2-infected without wasting, PCV2-infected with wasting, PCV2-infected with wasting and lymphoid depletion). The quantity of PCV2 DNA in diverse tissues was significantly differed among these groups. (One-way ANOVA test, $p<0.001$ ) Interestingly, PCV2-DNA load in tissues of PCV2-infected pigs without wasting and PCV2-infected pigs with wasting and lymphoid depletion were not significantly differed $(p=0.38)$, while they were all significantly higher when compared with PCV2-infected pigs with wasting-only. PCV2 DNA quantity in tissues was significantly higher in PCV2a and $2 \mathrm{~b}$ co-infected pigs compared to the PCV2b only-infected pigs (Wilcoxon test, $p=0.039$ ). The PCV2a and $2 \mathrm{~b}$ co-infected pigs had increased wasting and lymphoid depletion rate but it was not statistically significant. Therefore, this cross-sectional study suggested that PCV2 DNA load in tissues was diverse by clinical and histological findings. Furthermore, co-infection of PCV2a and $2 b$ affected to the PCV2 DNA load in tissues with increased rate of wasting and lymphoid depletion.
\end{abstract}

Keywords : clinical sign, genotype, PCV2a, PCV2b, quantification

\section{Introduction}

Porcine circovirus type 2 (PCV2) is a member of the circoviridae family, circovirus genus, a recently established virus family composed of small, non-enveloped viruses, with a circular, single-stranded DNA genome, which is now recognized as the essential infectious agent for the occurrence of postweaning multisystemic wasting syndrome (PMWS) in pigs [1, 3, 10]. PMWS was first identified in western Canada in 1996 [13], which causes significant economic losses to global pig industry and now it is seen as the major clinical manifestation of a range of porcine circovirus associated diseases (PCVADs). Porcine reproductive and respiratory syndrome virus is also known for a co-factor for PMWS with PCV2 [2, $16,26]$. PCVADs are becoming a major problem of the swine industry worldwide, so it's very important to diagnose and control PMWS and further control PCVADs in swine industry.

To diagnosis the PCVAD, clinical sign, histopathological study and PCV2 detection should be considered simultaneously. Since a study has shown that PCV2 burden in tissues is associated with clinical severity of PCVAD [14, 20], real-time polymerase chain reaction (PCR) as a rapid technique with high sensitivity and specificity has been studied for diagnosis of PCVAD, especially PMWS. Several previous real-time PCR for PCV2 quantification using a probe-based [7, 24, 27] or a $\mathrm{SyBr}$ green-based method [22] were established and used to investigate the relationship between PCV2 DNA load and the severity of PMWS. However, the diverse PCV2 DNA load in tissues even in the pigs with similar severity has made it hard to confirm the real-time PCR as a diagnostic tool for PMWS.

Recently the PCV2 was known to have two genotypes $[8,11,23]$. Since diverse terms were used to describe

*Corresponding author

Tel: +82-2-880-1255, Fax: +82-2-885-0263

E-mail: parkx026@snu.ac.kr

The first two authors equally contributed to this study. 
these genotypes, Grau-Roma and others proposed to define the term used for PCV2 genotype, Genogroup 1 and 2 which corresponded to PCV $2 b$ and $2 a$, the terms used in this study [11, 12]. Although a retrospective study showed that the PCV2b (PCV2 Genogroup 1) was more correlated with the PMWS than the PCV2a (PCV2 Genogroup 2), an animal experiment revealed that there were no type specific differences in virulence and each type shared cross-protection [25]. Therefore, additional information should follow the previous reports to understand these deputing results.

It was reported that the two genotypes of PCV2 were also circulating in Korea and they were both found in healthy, porcine dermatitis nephropathy syndrome and PMWS-affected pigs [4]. Along with this data, this study was focused on the genotyping and quantification of PCV2 in PCV2-positive pigs with different clinical symptoms from diverse regions of Korea to observe the correlation of clinical symptoms with quantity and genotypes of PCV2.

\section{Materials and Methods}

\section{Pigs and sample preparation}

Total thirty pigs from 28 to 100 days of age were included for the study. They were all conventional pigs (crossbreeding) from 2005 to 2006 submitted to the laboratory for the diagnosis. The information of the pigs was presented in Table 1. They were all PCV2-positive with a PCR [28]. The histopathology of superficial inguinal lymph nodes was performed to find lymphoid depletion, basophilic inclusion bodies and granulomatous inflammation. The PCV2-infected wasting pigs without lymphoid depletion were also selected for the study. To select the wasting pigs, all pigs were weighed before autopsy and compared with the average weight of the normal pigs at the same age. The reference data about normal weight per age were derived from 'Disease of swine' [9]. To avoid the inter-farm differences of growth rate, the normal weights of pigs in slow growth rate were chosen for the comparison. The regression curve was drawn to obtain standard formula of average weight per age. (Average weight $=0.0035 \times$ age $^{2}+0.0326 \times$ age + $2.08, \mathrm{R}^{2}=0.9999$ ) This formula was used to obtain the minimal normal weight in specific age to decide whether the pigs were wasting or not.

When the pigs were in autopsy, lung, heart, liver, spleen, kidney, tonsil, submaxillary lymph node, bronchial lymph node, mesenteric lymph node, inguinal lymph node and large intestine were collected in separate tube. Then, DNA were extracted from each organ using a commercial DNA extraction kit (QIAGEN, USA) and quantified by measuring at 260 of absorbance value, using spectrophotometer (Eppendorf, Germany).

\section{Preparation of standard plasmid DNA}

A 727 bp DNA fragment from ORF2 region (Forward primer: 5'-TTC GAA TTC AGC TAT GAC GTA TCC3', Reverse primer: 5'-TTT CTC GAG CAT TTA GGG TTT AAG-3') of the PCV2 genome was amplified and cloned into pMD18-T Vector (Takara, Japan) and transformed in Escherichia coli JM109 competent cells, creating a recombinant plasmid designated as pT-PCV2ORF2. The plasmid was purified and quantified to be used as standard for PCV2 DNA quantification.

\section{Real time PCR}

Briefly, PCV2-specific forward primer (5'-CCAGGA GGGCGTTGTGACT-3'), PCV2-speicif reverse primer (5'-CGCTACCGTTGGAGAAGGAA-3') and probe (5'AATGGCATCTTCAACACCCGCCTCT-3', labeled at 5' with FAM and at 3' with TAMRA) were used for the real-time PCR, following previous paper [24].

The reaction contained $500 \mathrm{nM}$ of each primer, 150 $\mathrm{nM}$ of probe, $12.5 \mu \mathrm{L}$ of TaqMan universal master mix (which includes amplitaq gold DNA polymerase, dNTP's with UTP, $\mathrm{MgCl} 2, \mathrm{ROX}$, amperase UNG and buffers) and $200 \mathrm{ng}$ of template. Reactions include organ samples and standard DNA (from $10^{9}$ to $10^{4} \mathrm{PCV} 2$ plasmid copies/ $\mu \mathrm{L}$ ) and negative control (using autoclaved nanopure water as template), both by triplicates, and performed in ABI PRISM 7000 sequence detection system (Applied Biosystems, USA) under $10 \mathrm{~min}$ at $95^{\circ} \mathrm{C}, 2 \mathrm{~min}$ at $50^{\circ} \mathrm{C}$ and 40 cycles of $15 \mathrm{sec}$ at $95^{\circ} \mathrm{C}, 1 \mathrm{~min}$ at $60^{\circ} \mathrm{C}$.

\section{Genotyping of PCV2}

A previously reported nested PCR for genotyping of PCV2a and $2 b$ was used in this study [21]. The DNA of lungs of each pig were used as templates for the nested PCR. VF-2 (5'-GAA GAA TGG AAG AAG CGG-3') and nested-R (5'-ACA GTC AGA ACG CCC TCC $\mathrm{T}-3^{\prime}$ ) primers were for the first round PCR to differentiate the PCV1 and PCV2. After the first PCR reaction, the second PCR was performed to differentiate the PCV2a and PCV2b. The primer sequences for PCV2a were 2a-F (5'-AAC AAT CCA CGG AGG 
Table 1. The information of pigs used in this study

\begin{tabular}{|c|c|c|c|c|c|c|c|}
\hline Pig no. & Day of age & Weight (Kg) & PRRSV* & $\mathrm{PCV} 2^{\dagger}$ & $\begin{array}{l}\text { Wasting/ } \\
\text { Normal }\end{array}$ & $\begin{array}{l}\text { Gross lesion of superficial } \\
\text { inguinal lymph nodes }\end{array}$ & $\begin{array}{l}\text { Lymphoid } \\
\text { depletion }\end{array}$ \\
\hline 1 & 55 & 8.75 & - & $+*$ & Wasting & Enlarged \& congested & + \\
\hline 2 & 45 & 11.8 & - & $+*$ & Normal & Enlarged & - \\
\hline 3 & 56 & N.A $A^{\S}$ & + & + & N.A & Congested & N.A \\
\hline 4 & 30 & 7.65 & - & + & Normal & Congested & - \\
\hline 5 & N.A & N.A & - & $+*$ & N.A & Normal & N.A \\
\hline 6 & 40 & 8.7 & + & + & Normal & Normal & - \\
\hline 7 & 55 & 13.35 & - & + & Normal & Congested & - \\
\hline 8 & 45 & 10 & + & + & Normal & Severely enlarged & - \\
\hline 9 & 80 & 22.7 & + & $+*$ & Wasting & Severely enlarged & + \\
\hline 10 & 55 & 15 & + & + & Normal & Normal & - \\
\hline 11 & 70 & 12.5 & + & + & Wasting & Severely enlarged & + \\
\hline 12 & 50 & 12 & + & + & Normal & Enlarged & - \\
\hline 13 & 50 & 7.25 & - & + & Wasting & Enlarged & + \\
\hline 14 & 58 & 13.5 & - & $+*$ & Wasting & Enlarged & + \\
\hline 15 & 28 & 4.2 & + & + & Wasting & Normal & - \\
\hline 16 & N.A & N.A & - & + & N.A & N.A & N.A \\
\hline 17 & 55 & 11.3 & - & + & Wasting & Normal & - \\
\hline 18 & 42 & 8 & + & $+*$ & Wasting & Enlarged & + \\
\hline 19 & 50 & 10.65 & + & + & Wasting & Enlarged & + \\
\hline 20 & 60 & 13 & + & + & Wasting & Severely enlarged & + \\
\hline 21 & 100 & 12 & + & + & Wasting & Normal & - \\
\hline 22 & 50 & 7.4 & + & + & Wasting & Congested & - \\
\hline 23 & 80 & 12.3 & - & $+*$ & Wasting & Normal & - \\
\hline 24 & 70 & 18 & - & + & Wasting & Severely enlarged & + \\
\hline 25 & 50 & N.A & - & + & N.A & Normal & - \\
\hline 26 & 40 & 10.1 & - & + & Normal & Enlarged \& congested & - \\
\hline 27 & 40 & 9.8 & - & + & Normal & Enlarged \& congested & - \\
\hline 28 & 50 & 8.9 & - & + & Wasting & Normal & - \\
\hline 29 & 70 & 18 & - & + & Wasting & Normal & - \\
\hline 30 & 30 & 4.7 & - & + & Wasting & Normal & - \\
\hline
\end{tabular}

* Porcine reproductive and respiratory syndrome virus (PRRSV), Detecting by Reverse transcriptase-nested polymerase chain reaction $(\mathrm{PCR})$ [17].

'Detecting by PCR [28].

Both positive to the porcine circovirus type 2 (PCV2)a and $2 \mathrm{~b}$.

$\S$ No data available.

AAG G-3') and 2a-R (5'-GGG ACC AAC AAA ATC TCY-3'), and for PCV2b were 2b-F (5'-CTG TTT TCG AAC GCA GTG-3') and 2b-R (5'-CTC AAA CCC CCG CTC TG-3'). The entire condition for the nested PCR was the same with the method of Lyoo et al. [21].

\section{Statistical analysis}

All data was sorted in Excel program (Microsoft, USA). To analyze the correlation between proportion of wasting and wasting + lymphoid depletion pigs in PCV2a and $2 \mathrm{~b}$ co-infected pigs ( 6 pigs) and PCV2b only-infected pigs (20 pigs), the Fisher's exact test was used. The ANOVA test was performed to evaluate the significant differences of the tissue distribution of PCV2 DNA in the pigs of PCV2-infected without wasting, PCV2-infected with wasting, PCV2-infected with wasting and lymphoid depletion. The Wilcoxon test was also used to compare PCV2 DNA load in PCV2a and 2b co-infected pigs and PCV2b-only infected pigs. All statistical analyses were performed using SPSS 12.0 program (USA). 


\section{Results}

\section{Clinical symptoms and quantity of PCV2 DNA}

This result was obtained from available pigs which had information about wasting and lymphoid depletion. The mean cycle threshold $(\mathrm{Ct})$ values of total organs in non-wasting PCV2-infected pigs (9 pigs) and PCV2infected pigs with wasting and lymphoid depletion (9 pigs) were significantly lower than PCV2-infected pigs

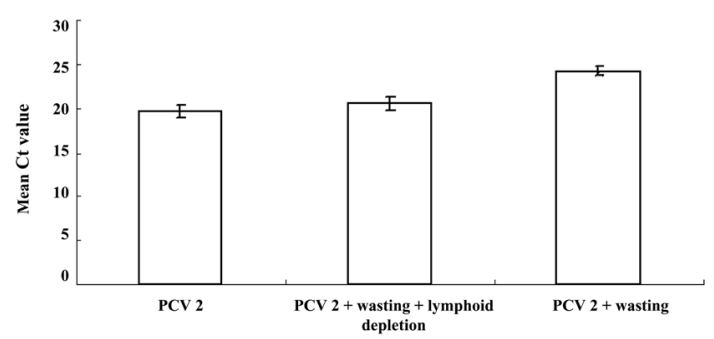

Fig. 1. PCV2-specific mean cycle threshold $(\mathrm{Ct})$ values of total organs in non-wasting porcine circovirus type 2 (PCV2)-infected, PCV2 + wasting and PCV2 + wasting + lymphoid depletion pigs. Significant differences of average $\mathrm{Ct}$ values among three groups were found by One-way ANOVA test $(p<0.001)$. The mean $\mathrm{Ct}$ values of nonwasting PCV2-infected and PCV2 + wasting + lymphoid depletion pigs were significantly lower than PCV2 + wasting pigs by student $t$-test $(p<0.001)$. No differences were found between non-wasting PCV2-infected and PCV2 + wasting + lymphoid depletion pigs $(p=0.38)$. with wasting-only (8 pigs), (Fig. $1, p<0.001$ ). These results were corresponded to $8.2,7.9$ and $6.9 \log$ PCV2 DNA copies $/ \mathrm{mL}$ in non-wasting PCV2-infected pigs, PCV2-infected pigs with wasting and lymphoid depletion and PCV2-infected pigs with wasting-only, respectively. The Mean Ct values of PCV2-infected pigs with wasting and lymphoid depletion and non-wasting PCV2-infected pigs were similar and not significantly different. $(p=$ $0.38)$

Tissue distribution of PCV2 DNA in the pigs of PCV2-infected without wasting, PCV2-infected with wasting, PCV2-infected with wasting and lymphoid depletion

The PCV2 DNA was evenly distributed in the lung, heart, liver, spleen, kidney, tonsil, submaxillary lymph node, bronchial lymph node, mesenteric lymph node, inguinal lymph node and large intestine (Fig. 2). The quantity of PCV2 DNA in different tissues was significantly lower in PCV2-infected pigs with wasting only.

\section{Genotypes and quantity of PCV2 DNA}

All pigs were shown to be positive to PCV2b in the genotype-specific nested PCR. Only 7 of 30 pigs were positive to PCV2a. To observe if there were any genotype-specific differences in the quantity of PCV2

目 PCV 2 PCV 2 + wasting + lymphoid depletion 8 PCV 2 + wasting

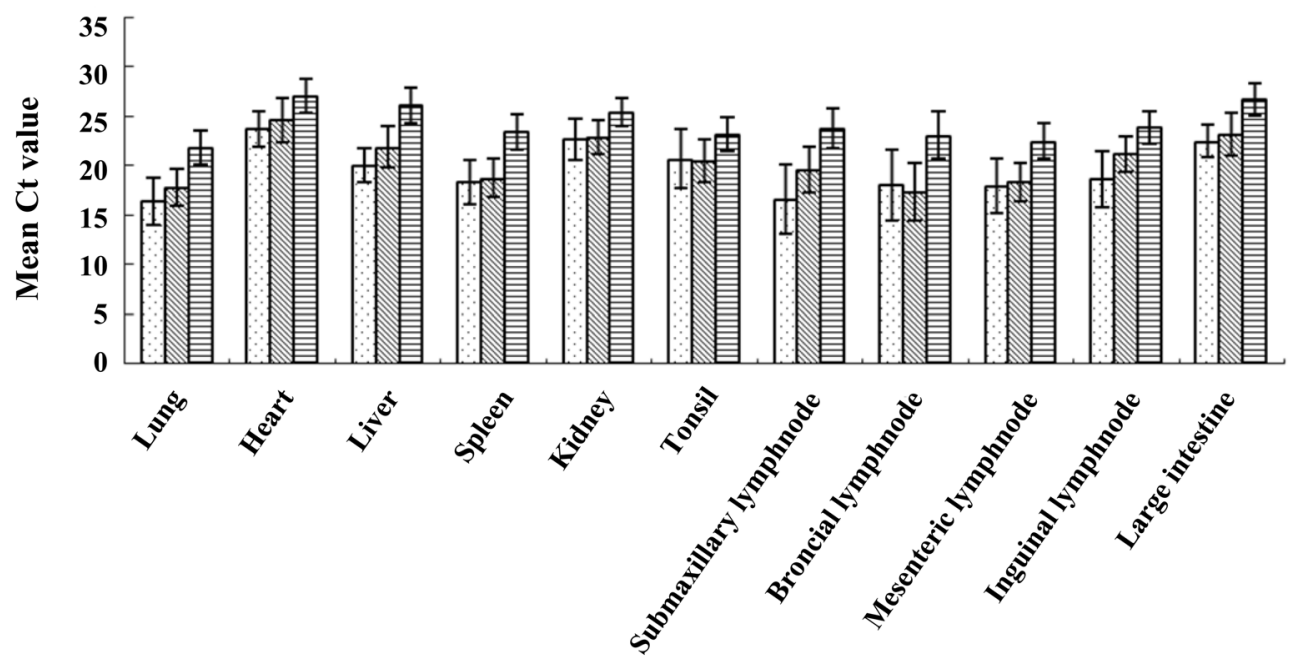

Fig. 2. The quantity of PCV2 DNA in different organs of PCV2 infected pigs with different clinical symptoms. Error bars indicate the standard error. 
Table 2. Comparison of average cycle threshold $(\mathrm{Ct})$ values between samples infected with PCV2b only or PCV2a + PCV2b

\begin{tabular}{ccc}
\hline \hline \multirow{2}{*}{ The type of PCV2 } & \multicolumn{2}{c}{ Type of comparison } \\
\cline { 2 - 3 } & Average of total organs & Lungs only \\
\hline PCV2b only $(23 / 30)^{*}$ & $23.1^{+*}(6.6)^{\S}$ & $21.0(7.1)$ \\
PCV2a + PCV2b $(7 / 30)$ & $17.2^{*}(6.6)$ & $15.4(6.9)$ \\
\hline
\end{tabular}

"no. of PCV2b only or PCV2a and $2 \mathrm{~b}$ co-infected pigs / Total pigs.

tmean $\mathrm{Ct}$ value.

Significantly different with the Wilcoxon two sample test $(p=0.039)$.

$\S_{\text {standard deviation. }}$

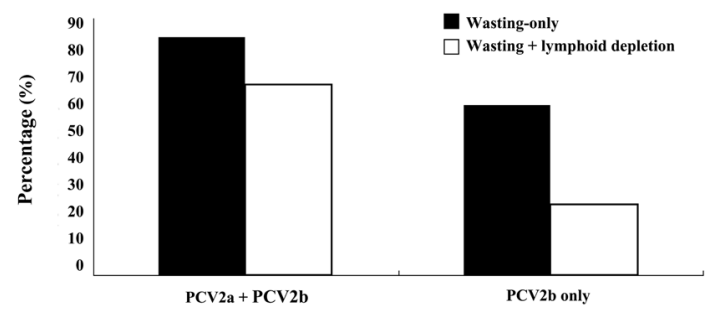

Fig. 3. The proportion of wasting and wasting+lymphoid depletion pigs in PCV2a and $2 \mathrm{~b}$ co-infected pigs (6 pigs) and PCV $2 b$ only-infected pigs (20 pigs). The differences between two groups were not significant in fisher's exact test (rate of wasting pigs, $p=0.38$; the rate of wasting + lymphoid depletion pigs, $p=0.14$ ).

DNA in tissues, average Ct values of total organs in PCV2a and $2 b$ co-infected pigs were compared with those of PCV2b only infected pigs. (Table 2) The average $\mathrm{Ct}$ value of PCV2a and $2 \mathrm{~b}$ co-infected pigs was lower than that of PCV2b-only infected pigs significantly. (Wilcoxon test, $p=0.039$ ) This meant that the PCV2 DNA load in the tissues was higher in PCV2a and $2 b$ co-infected pigs (8.9 log PCV2 DNA copies/mL) than PCV2b-only infected pigs (7.2 log PCV2 DNA copies/ $\mathrm{mL}$ ). The PCV2 DNA load of lungs were also higher in the co-infected pigs (9.4 log PCV2 DNA copies $/ \mathrm{mL}$ ) than PCV2-only infected pigs (7.8 log PCV2 DNA copies $/ \mathrm{mL}$ ) but that's not significant $(p=0.09)$.

\section{Genotypes of PCV2 and clinical symptoms}

To know whether genotype-specific differences could influence to the clinical symptoms, the proportion of pigs with wasting only or wasting/lymphoid depletion were compared in PCV2a and $2 \mathrm{~b}$ co-infected pigs (6 pigs) and PCV2b only-infected pigs (20 pigs) (Fig. 3). The rates of wasting or wasting/lymphoid depletion were relatively higher in the co-infected pigs than $\mathrm{PCV} 2 \mathrm{~b}$ only-infected pigs. However, this result was not significant in Fisher's exact test ( $p=0.38, p=0.14$, respectively).

\section{Discussion}

In this study, we could find significantly high quantity of PCV2 DNA in tissues from PCV2-infected pigs with wasting and lymphoid depletion compared to PCV2infected pigs with wasting-only. However, even normal pigs infected with PCV2 showed high quantity of PCV2 DNA which was similar to PCV2-infected pigs with wasting and lymphoid depletion. This might be due to the subclinical period between virus replication and clinical manifestation. In addition, the low PCV2 DNA load in PCV2-infected pigs with wasting-only might be recovering pigs which had had PMWS-associated lesions but were in the stage of virus elimination and recovering as mentioned by previous study [24].

Many studies had been performed to figure out the correlation between PCV2 DNA load and the severity of diseases, especially the PMWS. The previous studies suggested that the $10^{7}$ PCV2 DNA copies per $\mathrm{mL}$ of the sera was the threshold of PMWS diagnosis [5, 24, 27]. However, there was the high variability of PCV2 DNA load in the pigs of same clinical level of PMWS. Furthermore, recently published data indicated that the inter-laboratory results of quantitative real time PCR were not fully in agreement [17] and the authors proposed the standardization of laboratory threshold for the PMWS diagnosis. These factors had been a main problem in the PMWS diagnosis using real time PCR methods. Therefore, careful approach should be done to evaluate PCV2-associated diseases using real-time PCR method.

In this study, some pigs were also infected by PRRSV. Since PRRSV is also known for a co-factor for PMWS 
with PCV2 [2, 16, 26], the correlation of PRRSV infection and PCV2 DNA load was also studied. However, there was no significant effect of PRRSV infection to the PCV2 DNA load in tissues in this study (Wilcoxon test, $p=0.4$ ).

So far, there were deputing reports about genotypespecific virulence. Several retrospective studies suggested that the PCV2b was associated with PMWS $[6,18]$. Although Grau-Roma et al. [12]. also supported that the PCV2b (PCV2 type 1) was more correlated with the PMWS than the PCV2a (PCV2 type 2), an animal experiment revealed that there were no type specific differences in virulence and each type shared crossprotection [25].

In this study, among 30 pigs, PCV2a-only infected pigs could not be found. The only 7 pigs were PCV2a and $2 b$ co-infected pigs. Since PCV2b became dominant strain in Korea [4], it might be hard to find PCV2a-only infected pigs among 30 conventional pigs. Therefore, we could compare only PCV2a and 2b co-infected pigs and PCV2b-only infected pigs for the comparison of PCV2 DNA load. The PCV2 DNA load of PCV2a and 2b coinfected pigs was higher than that of PCV2b-only infected pigs significantly. (Wilcoxon test, $p=0.039$ ) Since the PCV2 DNA load of lung was relatively higher than the other organs in most pigs of this study, we also compared the quantity of PCV DNA in lung tissues of PCV2a and 2b co-infected pigs and PCV2b-only infected pigs. The PCV2 DNA load of lungs was also higher in the co-infected pigs but that's not significant $(p=0.09)$. Although increased rate of wasting and lymphoid depletion was observed in the PCV2a and $2 b$ co-infected pigs, it was not significantly supported by statistical analysis. However, recent study revealed that co-infection of PCV2a and $2 b$ increased the severity of PCV2-associated diseases [15]. Therefore, we could support that co-infection of PCV2a and 2b could affect to clinical severity as well as PCV2 DNA load in tissues.

\section{Conclusion}

PCV2 DNA load in tissues was diverse by clinical and histological findings. Furthermore, the quantity of PCV2 DNA in tissues was significantly higher in pigs coinfected with PCV2a and $2 b$ than pigs only infected with $\mathrm{PCV} 2 \mathrm{~b}$, inducing clinical severity.

\section{Acknowledgments}

This work was supported by a grant (Code\# 20070401034009) from Biogreen 21 Program, Rural Development Administration and by Research Institute for Veterinary Science, Korea.

\section{References}

1. Allan GM, Mc Neilly F, Meehan BM, Kennedy S, Mackie DP, Ellis JA, Clark EG, Espuna E, Saubi $\mathbf{N}$, Riera P, Bøtner A, Charreyre CE. Isolation and characterisation of circoviruses from pigs with wasting syndromes in Spain, Denmark and Northern Ireland. Vet Microbiol 1999, 66, 115-123.

2. Allan GM, McNeilly F, Ellis J, Krakowka S, Meehan B, McNair I, Walker I, Kennedy S. Experimental infection of colostrum deprived piglets with porcine circovirus 2 (PCV2) and porcine reproductive and respiratory syndrome virus (PRRSV) potentiates PCV2 replication. Arch Virol 2000, 145, 2421-2429.

3. Allan GM, McNeilly F, Kennedy S, Daft B, Clarke EG, Ellis JA, Haines DM, Meehan BM, Adair BM. Isolation of porcine circovirus-like viruses from pigs with a wasting disease in the USA and Europe. J Vet Diagn Invest 1998, 10, 3-10.

4. An DJ, Roh IS, Song DS, Park CK, Park BK. Phylogenetic characterization of porcine circovirus type 2 in PMWS and PDNS Korean pigs between 1999 and 2006. Virus Res 2007, 129, 115-122.

5. Brunborg IM, Moldal T, Jonassen CM. Quantitation of porcine circovirus type 2 isolated from serum/plasma and tissue samples of healthy pigs and pigs with postweaning multisystemic wasting syndrome using a TaqMan-based real-time PCR. J Virol Methods 2004, 122, 171-178.

6. Cheung AK, Lager KM, Kohutyuk OI, Vincent AL, Henry SC, Baker RB, Rowland RR, Dunham AG. Detection of two porcine circovirus type 2 genotypic groups in United States swine herds. Arch Virol 2007, 152, 1035-1044.

7. Chung WB, Chan WH, Chaung HC, Lien Y, Wu CC, Huang YL. Real-time PCR for quantitation of porcine reproductive and respiratory syndrome virus and porcine circovirus type 2 in naturally-infected and challenged pigs. J Virol Methods 2005, 124, 11-19. 
8. de Boisséson C, Béven V, Bigarré L, Thiéry R, Rose N, Eveno E, Madec F, Jestin A. Molecular characterization of Porcine circovirus type 2 isolates from post-weaning multisystemic wasting syndromeaffected and non-affected pigs. J Gen Virol 2004, 85, 293-304

9. Dewey CE, Straw BE. Herd examination. In: Straw BE, Zimmerman JJ, D'Allaire S, Taylor DJ (eds.). Diseases of Swine. 9th ed. pp. 3-14, Wiley-Blackwell, Iowa, 2006.

10. Ellis J, Hassard L, Clark E, Harding J, Allan G, Willson P, Strokappe J, Martin K, McNeilly F, Meehan B, Todd D, Haines D. Isolation of circovirus from lesions of pigs with postweaning multisystemic wasting syndrome. Can Vet J 1998, 39, 44-51.

11. Gagnon CA, Tremblay D, Tijssen P, Venne MH, Houde A, Elahi SM. The emergence of porcine circovirus $2 \mathrm{~b}$ genotype (PCV-2b) in swine in Canada. Can Vet J 2007, 48, 811-819.

12. Grau-Roma L, Crisci E, Sibila M, López-Soria S, Nofrarias M, Cortey M, Fraile L, Olvera A, Segalés J. A proposal on porcine circovirus type 2 (PCV2) genotype definition and their relation with postweaning multisystemic wasting syndrome (PMWS) occurrence. Vet Microbiol 2008, 128, 23-35.

13. Harding JCS, Clark EG. Recognizing and diagnosing postweaning multisystemic wasting syndrome (PMWS). Swine Health Prod 1997, 5, 201-203.

14. Harding JCS, Baker CD, Tumber A, McIntosh KA, Parker SE, Middleton DM, Hill JE, Ellis JA, Krakowka S. Porcine circovirus-2 DNA concentration distinguishes wasting from nonwasting pigs and is correlated with lesion distribution, severity, and nucleocapsid staining intensity. $\mathrm{J}$ Vet Diagn Invest 2008, 20, 274-282.

15. Harding JCS, Ellis JA, McIntosh KA, Krakowka S. Dual heterologous porcine circovirus genogroup $2 \mathrm{a} / 2 \mathrm{~b}$ infection induces severe disease in germ-free pigs. Vet Microbiol 2010, 145, 209-219.

16. Harms PA, Sorden SD, Halbur PG, Bolin SR, Lager KM, Morozov I, Paul PS. Experimental reproduction of severe disease in $\mathrm{CD} / \mathrm{CD}$ pigs concurrently infected with type 2 porcine circovirus and porcine reproductive and respiratory syndrome virus. Vet Pathol 2001, 38, 528-539.

17. Hjulsager CK, Grau-Roma L, Sibila M, Enøe C, Larsen L, Segalés J. Inter-laboratory and inter-assay comparison on two real-time PCR techniques for quantification of PCV2 nucleic acid extracted from field samples. Vet Microbiol 2009, 133, 172-178.

18. Horlen KP, Schneider P, Anderson J, Nietfeld JC, Henry SC, Tokach LM, Rowland RRR. A cluster of farms experiencing severe porcine circovirus associated disease: Clinical features and association with the PCV2b genotype. J Swine Health Prod 2007, 15, 270278.

19. Kono Y, Kanno T, Shimizu M, Yamada S, Ohashi S, Nakamine M, Shirai J. Nested PCR for detection and typing of porcine reproductive and respiratory syndrome (PRRS) virus in pigs. J Vet Med Sci 1996, 58, 941-946.

20. Krakowka S, Ellis J, McNeilly F, Waldner C, Allan G. Features of porcine circovirus-2 disease: correlations between lesions, amount and distribution of virus, and clinical outcome. J Vet Diagn Invest 2005, 17, 213-222.

21. Lyoo KS, Kim HB, Joo HS. Evaluation of a nested polymerase chain reaction assay to differentiate between two genotypes of porcine circovirus-2. J Vet Diagn Invest 2008, 20, 283-288.

22. McIntosh KA, Tumber A, Harding JCS, Krakowka S, Ellis JA, Hill JE. Development and validation of a SYBR green real-time PCR for the quantification of porcine circovirus type 2 in serum, buffy coat, feces, and multiple tissues. Vet Microbiol 2009, 133, 23-33.

23. Olvera A, Cortey M, Segalés J. Molecular evolution of porcine circovirus type 2 genomes: Phylogeny and clonality. Virology 2007, 357, 175-185.

24. Olvera A, Sibila M, Calsamiglia M, Segalés J, Domingo M. Comparison of porcine circovirus type 2 load in serum quantified by a real time PCR in postweaning multisystemic wasting syndrome and porcine dermatitis and nephropathy syndrome naturally affected pigs. J Virol Methods 2004, 117, 75-80.

25. Opriessnig T, Ramamoorthy S, Madson DM, Patterson AR, Pal N, Carman S, Meng XJ, Halbur PG. Differences in virulence among porcine circovirus type 2 isolates are unrelated to cluster type $2 \mathrm{a}$ or $2 \mathrm{~b}$ and prior infection provides heterologous protection. $\mathrm{J}$ Gen Virol 2008, 89, 2482-2491.

26. Rovira A, Balasch M, Segalés J, García L, PlanaDurán J, Rosell C, Ellerbrok H, Mankertz A, Domingo M. Experimental inoculation of conventional pigs with porcine reproductive and respiratory syndrome virus and porcine circovirus 2. J Virol 2002, 76, 3232- 
14 Hye Kwon Kim, Yuzi Luo, Hyoung Joon Moon, Seong Jun Park, Se Mi Rho, Jae Yeon Han, Van Giap Nguyen, Bong Kyun Park

3239.

27. Segalés J, Calsamiglia M, Olvera A, Sibila M, Badiella L, Domingo M. Quantification of porcine circovirus type 2 (PCV2) DNA in serum and tonsillar, nasal, tracheo-bronchial, urinary and faecal swabs of pigs with and without postweaning multisystemic wasting syndrome (PMWS). Vet Microbiol 2005, 111, 223-229.

28. Yang JS, Song DS, Kim SY, Lyoo KS, Park BK. Detection of porcine circovirus type 2 in feces of pigs with or without enteric disease by polymerase chain reaction. J Vet Diagn Invest 2003, 15, 369-373. 